\title{
Cholesterol pleural effusion in rheumatoid lung disease
}

\author{
G. C. FER GUSON \\ From the Chest Clinic, Dundee, and the Department of Tuberculosis, University of St. Andrews
}

Cholesterol pleural effusion is a rare condition. According to Moll and Fowweather (1940), Malaguti collected 44 cases from the literature up to 1929. However, I have been able to read only 39 case reports since the original by Churton in 1882 , the majority being in the non-English literature. This paper describes a further two patients, who are of particular interest in that for the first time there is in one case a full postmortem report with histological appearances and, in both, evidence that rheumatoid lung disease was an aetiological factor.

\section{CASE I}

P. D., a 39-year-old man employed as a semi-skilled loom mechanic, or tenter, developed rheumatoid arthritis in 1938. Two months before the onset of his arthritis he was said to have had a right-sided pneumonia. In 1951 he was admitted to Bridge of Earn Hospital for further treatment of the arthritis and was found to have a right-sided pleural effusion. Aspiration of this revealed numerous cholesterol crystals, the cell count being $65 \%$ lymphocytes and $35 \%$ polymorphs, while the fluid was sterile on culture and negative for Mycobacterium tuberculosis. His condition settled and he was allowed home. (A brother suffered from pulmonary tuberculosis and rheumatoid arthritis.)

He remained well until 1956, when he was admitted to Ashludie Chest Hospital with a six months' history of tiredness, productive cough, and exertional dyspnoea. Clinical examination revealed low-grade fever, severe rheumatoid deformity affecting the hands, elbows, shoulders, and knees, and a right-sided pleural effusion.

Investigations were as follows: Haemoglobin concentration 13 g. $/ 100 \mathrm{ml}$. $(88 \%)$, W.B.C. $10,000 /$ mm. ${ }^{3}$ with normal differential count. E.S.R. 25 $\mathrm{mm}$./ first hour. Serum albumin $3 \mathrm{~g}$., globulin $2.9 \mathrm{~g}$., cholesterol $110 \mathrm{mg} . / 100 \mathrm{ml}$. Sputum culture on four occasions was negative for Myco.tuberculosis. A chest radiograph revealed reticulation in both lung fields and a small right pleural effusion (Fig. 1). The pleural effusion was white and opalescent and con- tained numerous cholesterol crystals but no cells. It was sterile and negative on culture for Myco. tuberculosis on two occasions. Treatment consisted of various antibiotics plus repeated aspiration, and the fusion cleared almost completely.

In 1957 he was admitted to Maryfield Hospital with a two weeks' history of productive cough and breathlessness. A chest radiograph revealed a fresh inflammatory lesion at the right base which responded to penicillin and tetracycline. He was followed up as an outpatient, and in 1958 his condition deteriorated with wheezing and worsening of his joint symptoms. Treatment with phenylbutazone and prednisone, 5 mg. b.d., for two months produced considerable improvement.

In 1959 he was readmitted to Maryfield Hospital on two occasions. The first was in June with a history of severe chest pain, and a diagnosis of bilateral bronchopneumonia with basal effusions and early cardiac failure was made. He responded to treatment with tetracycline and mersalyl and was discharged, but was readmitted in October with further severe chest pain and breathlessness. A diagnosis of myocardial infarction was made ; anticoagulant treatment was started but he died three days later.

Post-mortem examination showed a recent myocardial infarct involving the septum and a healed infarct in the postero-lateral wall of the right ventricle. The left coronary artery was grossly narrowed and the right occluded by thrombus $4 \mathrm{~cm}$. from its origin. The trachea and bronchi contained pus. The lungs, which were fibrotic and showed marked irregular emphysema, felt nodular, and in the right lower lobe nodules were visible, one of which showed central calcification. A long-standing pleural effusion was present on the left side, and the visceral pleura was coated with a thick layer of fatty material.

The histological appearances were strongly suggestive of rheumatoid lung disease (Fig. 2). There was a widespread granulomatous process with round cell infiltration, areas of necrosis, and palisading of histiocytes. Lymphoid follicles were conspicuous and there was thickening and round cell infiltration of the walls of the arterioles. The pleura was greatly thickened by a deposit of fibrinoid material probably representing the organization of fibrin, and containing numerous cholesterol clefts (Fig. 3). 


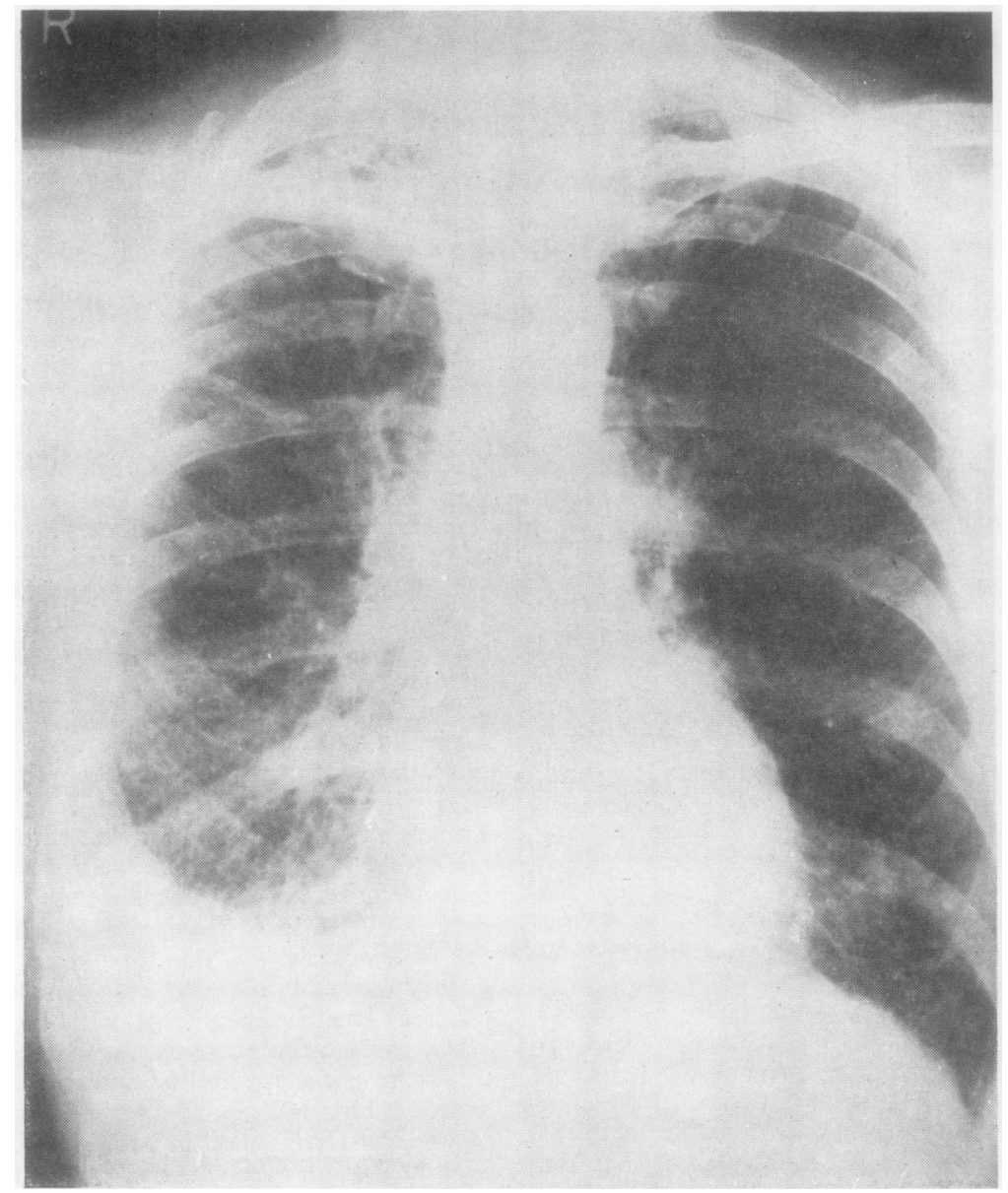

FIG. 1. Case I. Chest radiograph in 1956 shows bilateral reticulation affecting mainly the lower zones and a small right pleural effusion.

\section{CASE II}

T. B., a 54 year-old man employed as a semi-skilled draughtsman or stock-tracer, was discovered on routine miniature radiography in February 1965 to have a left-sided pleural effusion. He gave a history of mild rheumatoid arthritis affecting the hands in 1962, which improved after a short course of phenylbutazone. In January 1965 he had sustained a minor injury to the left chest, but there was no history of chest illness, and a previous miniature film in 1963 had shown only minimal pleural thickening at the left base. There was no family history of arthritis or chest trouble.

On admission to hospital he was found to be obese and to have minimal finger clubbing, but he was afebrile and had no joint abnormalities. There were signs of a left pleural effusion but no other abnormal physical signs, and a chest radiograph was normal apart from the effusion (Fig. 4). Investigations: Mantoux 100 T.U. $15 \mathrm{~mm}$. induration. E.S.R. $21 \mathrm{~mm}$. first hour (Westergren). Laryngeal swabs negative for Myco. tuberculosis on three occasions. Blood count. serum proteins, and electrophoresis were all normal, and serum cholesterol was $275 \mathrm{mg}$. $/ 100 \mathrm{ml}$. R.A. latex and L.E. latex tests were negative and no L.E. cells were found in the peripheral blood, but subsequently the R.A. latex test was positive on three occasions and the Rose-Waaler test was positive at a titre of 1 in 8. The pleural fluid was opalescent and shimmering and contained numerous cholesterol crystals. Its cholesterol content on three occasions was 248,105 , and $120 \mathrm{mg} . / 100 \mathrm{ml}$. , and it also contained albumin $3 \mathrm{~g} . / 100 \mathrm{ml}$. and globulin $3 \mathrm{~g} . / 100 \mathrm{ml}$. Culture was sterile and negative for Myco. tuberculosis on three occasions. The deposit also contained polymorphs, lymphocytes, and serosal cells, but no malignant cells were found despite three separate examinations. 


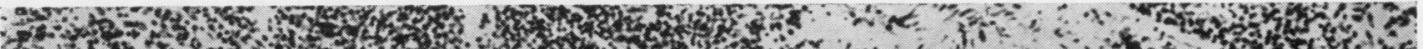

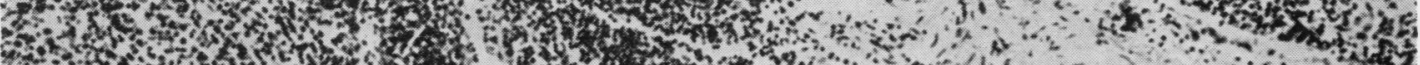

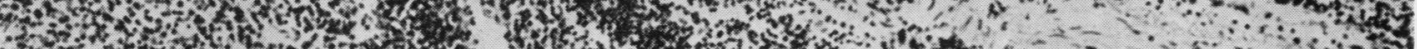
F. 6.0.

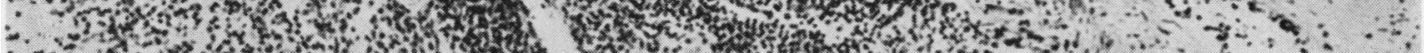

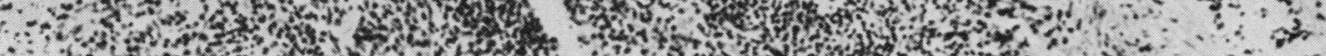

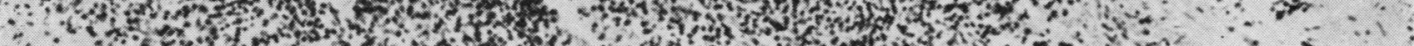
A

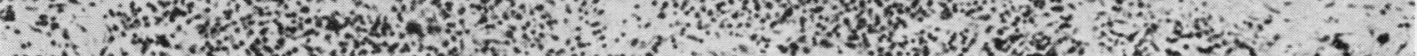
2.

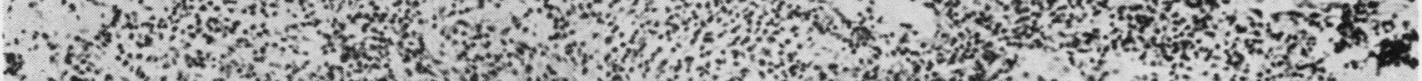

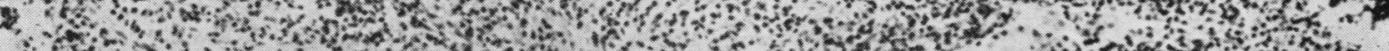
67 C. n-

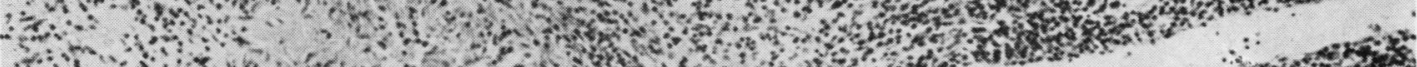

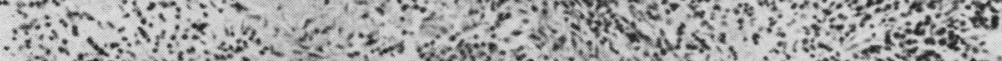
ats

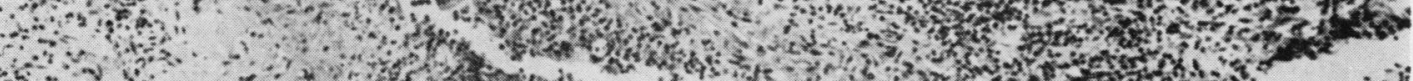
40 ond $\therefore$ -

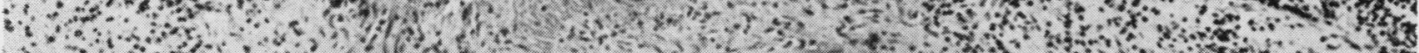

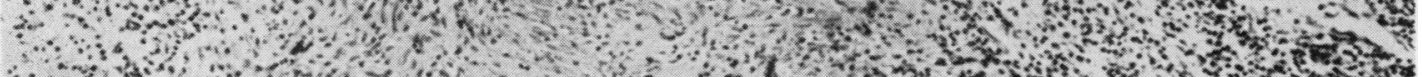

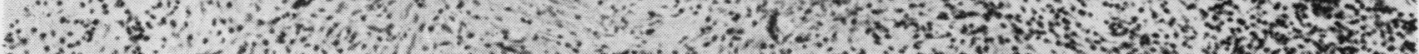

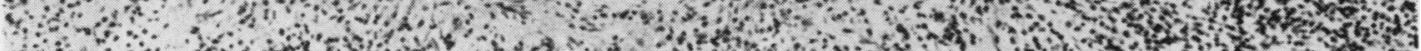

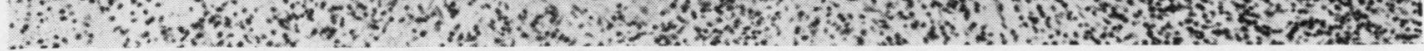

FIG. 2. Case I. Section of lung showing granuloma with necrotic focus surrounded by lymphocytes and palisading of histiocytes with plasma cells in the walls of the arterioles. Arterioles show thickening and lymphocytic infiltration. $\times 120$.

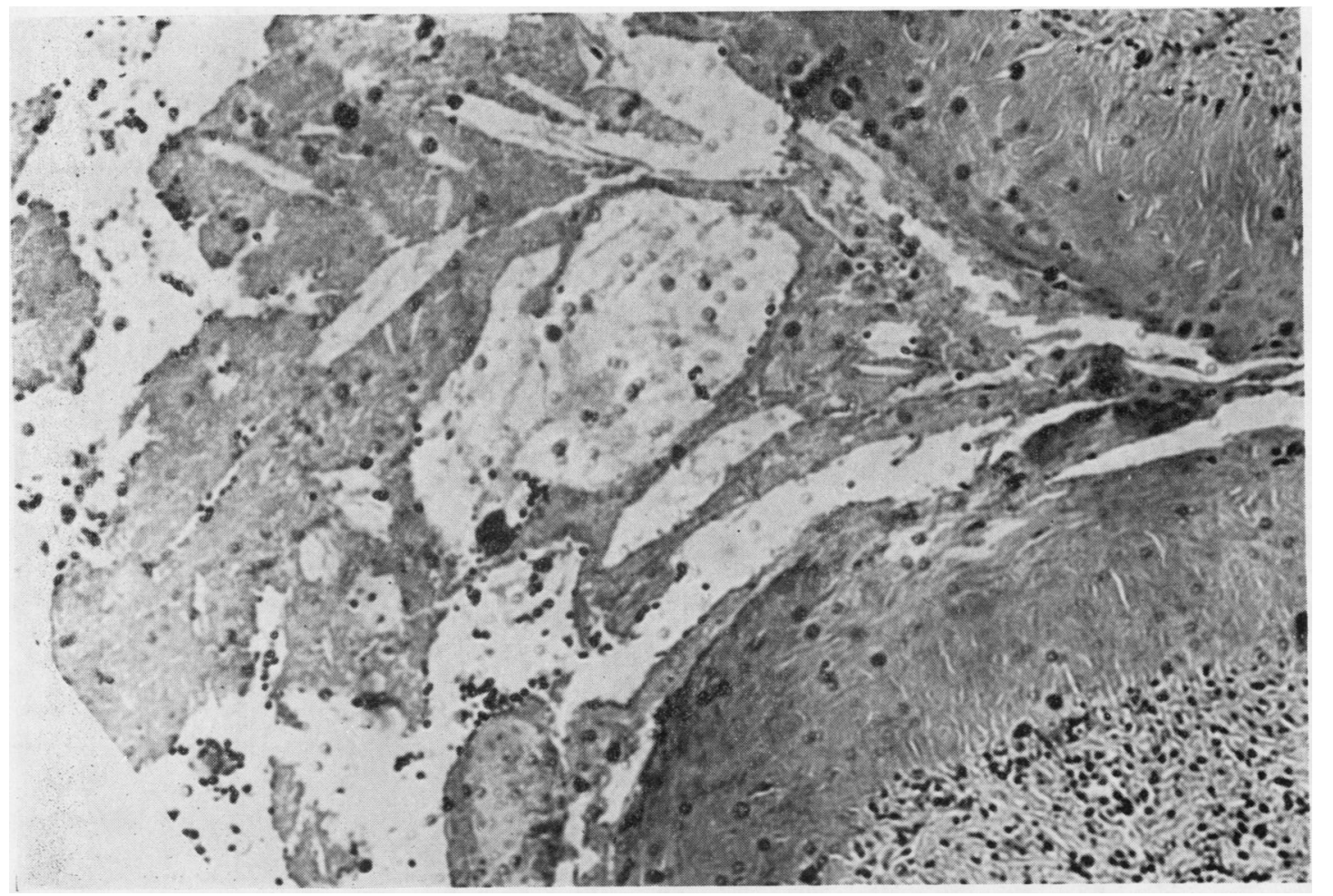

FIG. 3. Case I. Section of lung showing markedly thickened pleura with cholesterol clefts. 


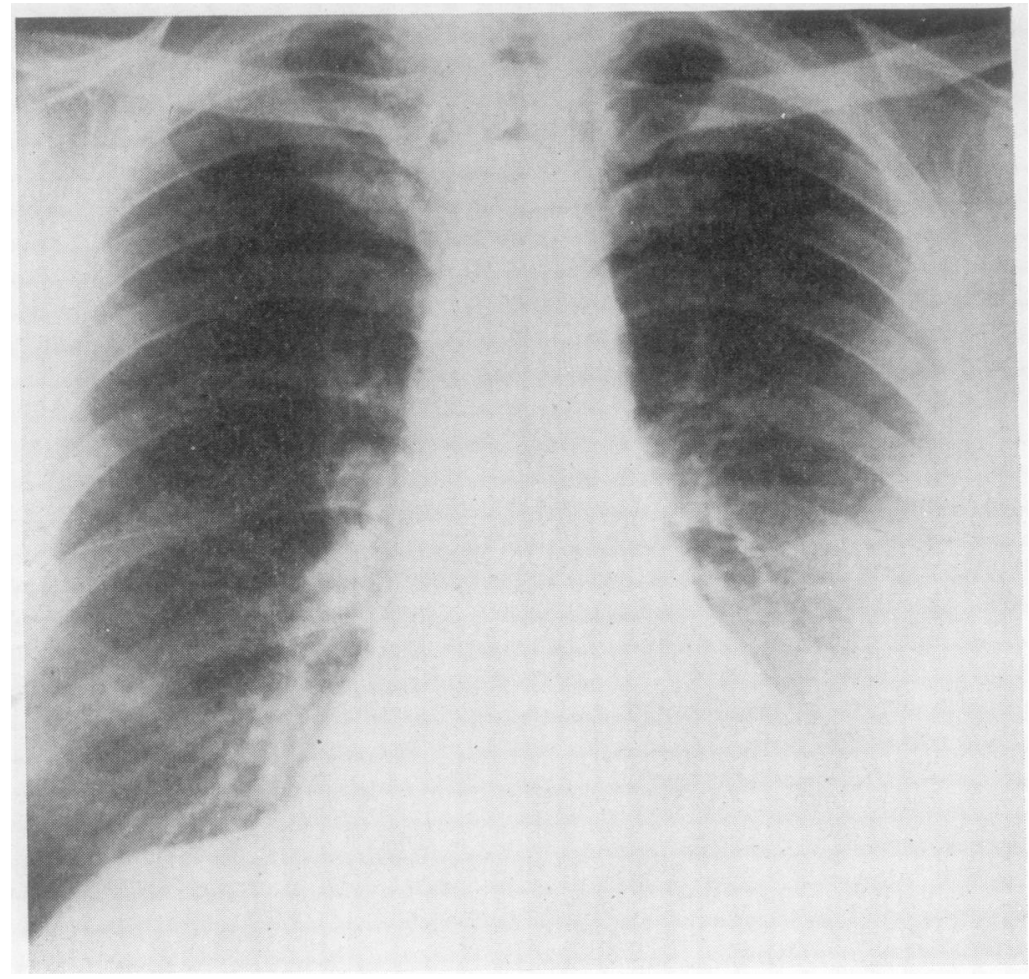

FIG. 4. Case II. Chest radiograph in February 1965, showing left pleural effusion but otherwise clear lung fields.

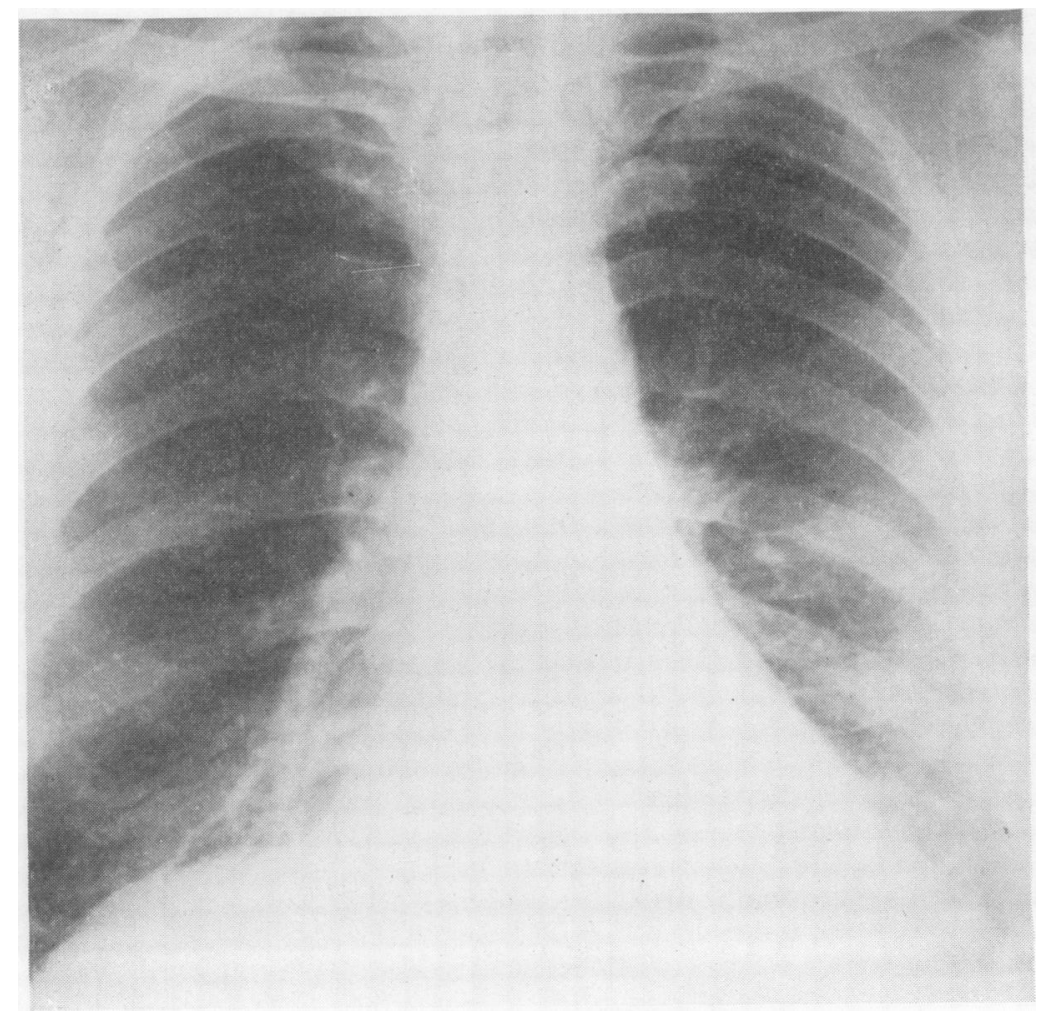

FIG. 5. Case II. Chest radiograph in November 1965, showing almost complete resolution with steroid therapy. 
Pleural biopsy showed a chronic inflammatory process suspicious of tuberculosis. Repeated aspiration produced partial resolution and he was allowed home.

In May 1965 it was found that the effusion had recurred to its former size. Aspiration was repeated and again no malignant cells were found on cytological examination. The effusion recurred again in July and treatment was begun with cachets giving a total daily dose of $12 \mathrm{~g}$. P.A.S. plus $300 \mathrm{mg}$. isoniazid. There was no improvement by October 1965 , so the anti-tuberculous chemotherapy was discontinued and prednisolone, $20 \mathrm{mg}$. daily, was started. A month later the chest radiograph showed that the effusion had almost completely resolved (Fig. 5). This improvement has been maintained following discontinuation of the steroid therapy.

\section{DISCUSSION}

The first recorded case was that of Churton in 1882, summarized as 'Double haemorrhagic pleurisy. Degeneration of cells with formation of cholesterine ; subsequent empyema on right side, operation and recovery ; followed by empyema on left side, septicaemia and death'. Later cases have presented a fairly uniform picture. The effusion is chronic, benign, and recurrent, without fever or toxaemia, the symptoms being generally limited to slight cough, chest discomfort, or exertional dyspnoea. The fluid itself, which may be clear, turbid, or haemorrhagic, nevertheless has a characteristic opalescence or sheen which in contrast to chylous effusions fails to clear with alkali or ether. Microscopy reveals numerous typical polyhedric crystals of cholesterol. Cells may be numerous, scanty or degenerate, and culture is usually sterile. The true incidence of these effusions may be greater than is usually accepted, as chest aspirations are frequently entrusted to the most junior medical staff, who may not unnaturally fail to recognize the unusual character of the fluid.

There are only two previous post-mortem reports, those of Churton (1882) and Stein (1932), but in neither is there any mention of the histological appearances. Both emphasize the gross pleural thickening with calcification and such rigidity that the pleural sac could be removed like a cast. In the latter case the cause of death was tuberculous meningitis.

In general, repeated aspiration has been the only treatment, but one case (Frew and CampbellFowler, 1956) is said to have improved on antituberculous chemotherapy. The commonest associated condition is active pulmonary tuberculosis, which was present in 14 out of the 39 cases reported in the literature. In the rest, no definite
T A B L E

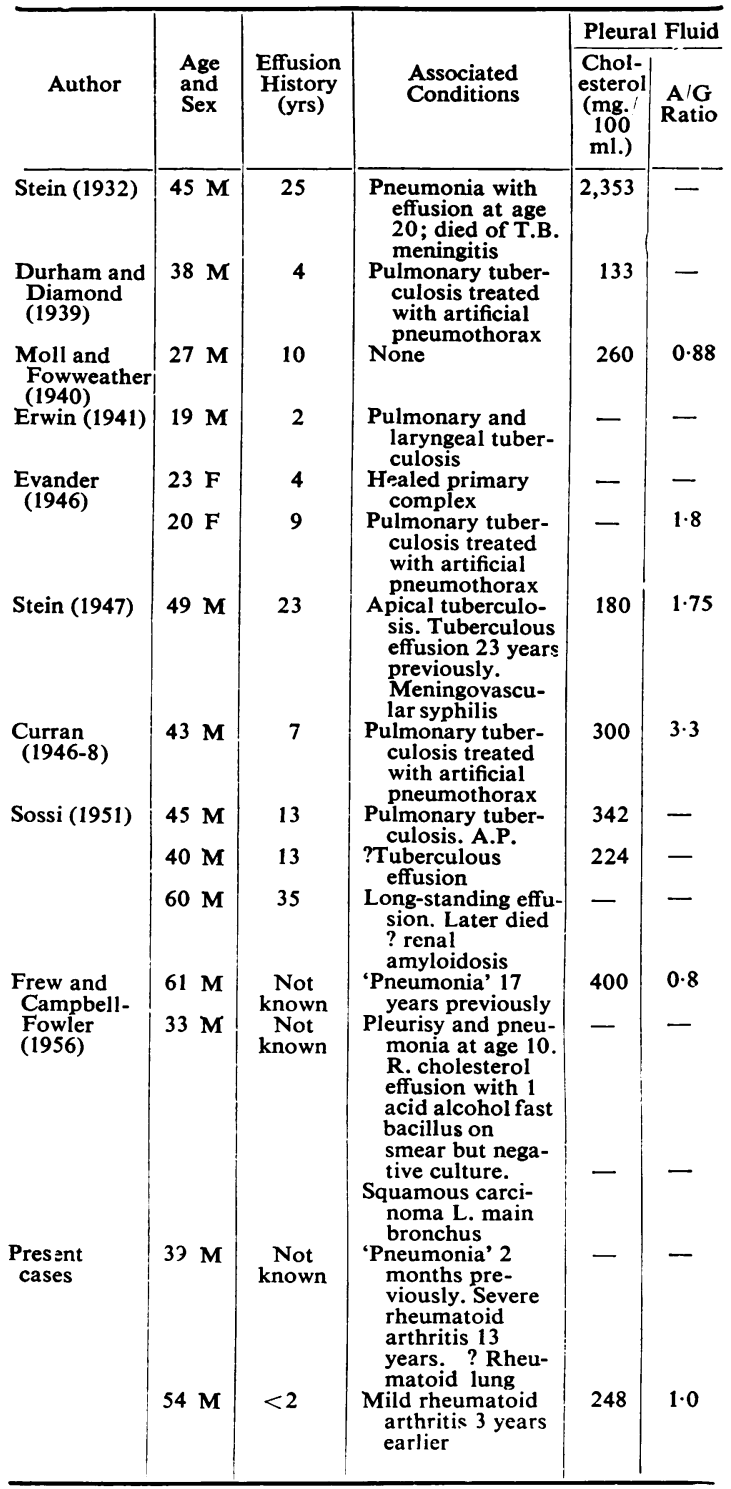

factor was incriminated, but in the present two cases there is evidence to suggest that the underlying process was rheumatoid lung disease. Both had clinical and serological evidence of rheumatoid arthritis, and in case $I$ the radiological appearances were compatible with and the histology strongly suggestive of 'rheumatoid lung'. In case II the effusion could have been tuberculous, but there is no evidence to support this, and the occurrence of isolated pleural effusions as a manifesta- 
tion of rheumatoid disease is now well recognized (Ward, 1961).

So far as the actual mechanism of cholesterol deposition is concerned, Weems (1918) considered that ageing or chronic effusions produced gross pleural thickening which reduced the resorptive power of the pleura and allowed cholesterol to accumulate. Desbordes (1938) and Desbordes and Lévy (1938), investigating the cholesterol content of various pathological fluids, found that they could cause precipitation of cholesterol by decreasing the albumin/globulin ratio to less than unity. Moll and Fowweather (1940) in their case found an albumin/globulin ratio of 0.88 and applied this theory to cholesterol effusions, but it has not been borne out by subsequent experience (see Table). These authors have also postulated that contact with a subpleural caseous focus containing cholesterol would help to cause precipitation.

Other authors have considered the cholesterol to be a breakdown product, whether of tubercle bacilli, red cells, or lymphocytes. It seems unlikely that tubercle bacilli would be present in sufficiently large numbers, and although the cholesterol/cholesterol ester ratio in the effusions resembles that of red cells, the haemorrhage in such cases would have to be gross. A lymphocytic origin seems the most likely, and this conclusion was reached by a recent Italian symposium (Candela, 1958).

All authors are agreed that these effusions are not associated with any alteration in the serum cholesterol level or clinical evidence of disturbed cholesterol metabolism such as xanthomata.

The Table shows that in most cases of cholesterol effusion there is a long effusion history, and chronicity is probably the most important single factor leading to their formation, whatever the actual mechanism. With the decline of tuberculosis the aetiology of chronic pleural effusions has become more varied, and the cases presented here are a reflection of the increasing importance of rheumatoid disease in this field.

\section{SUMMARY}

Two cases of cholesterol pleural effusion are described, in both of which it is probable that the underlying condition was rheumatoid lung disease. The literature is reviewed and the conclusion is reached that the main aetiological factor is chronicity of effusions from whatever cause.

I wish to thank Dr. Helen L. Duguid and Dr. William Guthrie, who carried out the pathological studies in the first case, and Dr. R. N. Johnston for help and advice in the preparation of this paper.

\section{REFERENCES}

Candela, A. (1958). La pleurite colesterinica. Lotta c. Tuberc., 28, 997

Churton, T. (1882). Double haemorrhagic pleurisy: Degeneration of cells with formation of cholesterine; subsequent empyema on right side, operation and recovery; followed by empyema on left side, septicaemia and death. Trans. clin. soc. Lond., 15, 19.

Curran, T. M. (1946-8). Cholesterol pleural effusion. Trans. Tuberc Soc. Scot., p. 51 .

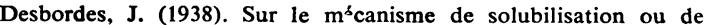
précipitation du cholestérol dans le sérum ou les liquides pathologiques (pouvoir cholestérolytique). C.R. Soc. Biol.(Paris), 127, 869.

and Lévy, D. (1938). Sur le taux protéines et l'équilibre sérine globuline dans divers liquides d'épanchements (liquide d'ascite, liquides pleuraux). Ibid., 127, 494.

Durham, W. R., and Diamond, S. (1939). Cholesterol pleurisy. Med. Bull. Veterans' Adm. (Wash.), 16, 12.

Erwin, G. S. (1941). Cholesterous pleural effusion. Brit. J. Tuberc., $35,25$.

Evander, L. C. (1946). Cholesterol pleural effusion. Amer. Rev. Tuberc., 54, 504.

Frew, H. W. O., and Campbell-Fowler, C. (1956). Cholesterol pleural effusion. Practitioner, 176, 416.

Moll, H. H., and Fowweather, F. S. (1940). Cholesterol pleura effusion. J. Path. Bact., 61, 37.

Sossi, O. (1951). Considerazioni su alcuni casi di pleurite colesterinica. Ann. Inst. Forlanini, 13, 247.

Stein, H. F. (1932). Cholesterol-thorax in tuberculosis (Cholesterol pleurisy). Arch. intern. Med., 49, 421.

- (1947). Cholesterol pleural effusion. Amer. Rev. Tuberc. 56, 305 .

Ward, R. (1961). Pleural effusion and rheumatoid disease. Lancet, 2 1336.

Weems, B. F. (1918). Cholesterohydrothorax. Amer. J. med. Sci., 156, 20. 